\title{
The argument from expert opinion as other-oriented reference in disciplinary discussions
}

\author{
Antonio Bova ${ }^{\mathrm{a} *}$ \\ ${ }^{a}$ Institute of Argumentation, Linguistics and Semiotics (IALS), Università della Svizzera italiana \\ (USI), Lugano, Switzerland \\ Francesco Arcidiacono \\ Research Department, University of Teacher Education BEJUNE, Bienne, Switzerland
}

Corresponding author (institutional address) (please use this address for correspondence and proofs):

Antonio Bova

Institute of Argumentation, Linguistics and Semiotics (IALS)

Università della Svizzera italiana (USI)

Via G. Buffi 13

6904 Lugano

Switzerland

Email: antonio.bova@usi.ch

\section{Acknowledgements}

The Swiss National Science Foundation under Grant number P2TIP1_148347 supported this work.

\begin{abstract}
This paper aims to investigate the types of source on which students base the arguments from expert opinion when used to convince their teacher and classmates to accept their standpoint during disciplinary discussions. Using the model of a critical discussion integrated with the Argumentum Model of Topics as analytical approach, a corpus of 66 arguments from expert opinion were analyzed. The results show that students in most cases refer to scholars and their scientific notions and theories as source of expertise (other-oriented argument). Less frequently, students refer to themselves and their previous personal experience as source of expertise (self-oriented argument).
\end{abstract}

Keywords: argumentation, Argumentum Model of Topics, classroom discourse, expert opinion, model of a critical discussion 


\title{
The argument from expert opinion as other-oriented reference in disciplinary discussions
}

\begin{abstract}
This paper aims to investigate the types of source on which students base the arguments from expert opinion when used to convince their teacher and classmates to accept their standpoint during disciplinary discussions. Using the model of a critical discussion integrated with the Argumentum Model of Topics as analytical approach, a corpus of 66 arguments from expert opinion were analyzed. The results show that students in most cases refer to scholars and their scientific notions and theories as source of expertise (other-oriented argument). Less frequently, students refer to themselves and their previous personal experience as source of expertise (self-oriented argument).
\end{abstract}

Keywords: argumentation, Argumentum Model of Topics, classroom discourse, expert opinion, model of a critical discussion 


\section{Introduction}

In the learning contexts, argumentation is not a heated exchange between rivals that results in winners and losers, or an effort to reach a mutually beneficial compromise; rather it is a form of "logical discourse whose goal is to tease out the relationship between ideas and evidence" (Duschl et al., 2007: 33). Argumentation enables students to engage in knowledge construction, shifting the focus from rote memorization of notions and theories to a complex scientific practice in which they construct and justify knowledge claims (Kelly and Chen, 1999; Sandoval and Reiser, 2004). Notwithstanding, current research indicates that learning how to engage in productive scientific argumentation to propose and justify an explanation through argument is difficult for students. Thus, empirical research that examines how students generate arguments has become an area of major concern for scholars interested in argumentation and education.

The present study intends to provide a further contribution to the line of research on studentgenerated arguments. In line with other scholars (Newton et al., 1999; Osborne, 2005; Sampson and Clark, 2008; Stein and Albro, 2001), in this study the term "argument" refers to the artifacts that a student creates to articulate and justify his/her standpoint, whereas the term "argumentation" refers to the process of constructing these artifacts. This study specifically focuses on the learning context of higher education and sets out to investigate the arguments from expert opinion used by graduate students in Developmental Psychology during the disciplinary discussions with their teacher and with their classmates, i.e., task-related discussions concerning the discipline taught in the course. We will refer to the definition of argument from expert opinion as the notion of epistemic authority elaborated by Walton (1997), namely, a relationship between two individuals where one is an expert in a field of knowledge and accordingly his/her opinion, when stated within an argumentative discussion, is essentially an appeal to expertise.

It is not a goal of the present study to make an assessment of the argument from expert opinion advanced by students, i.e. deciding whether or not a certain argument is fallacious ${ }^{1}$. Rather, our purpose is to answer the following question: "What type of source do students base on the arguments from expert opinion used during disciplinary discussions in the classroom?" This research question will be answered by means of a small-scale corpus study, in order to provide a "data-close" analysis of the argumentative dynamics in the classroom. In this endeavor, we have opted for an idiographic methodology based on the contemporary argumentation theory. The object of investigation will be the argumentative discussions between students and teacher, as well as among students, occurring during their ordinary lessons, rather than an ad hoc setting created to favor the beginning of argumentative discussions. The analytical approach for the analysis of the argumentative discussions relies on the pragma-dialectical model of a critical discussion (van Eemeren and Grootendorst, 2004), integrated with the Argumentum Model of Topics (AMT) (Rigotti and Greco Morasso, 2010).

In the first part of the paper, we will review the most relevant studies focusing on argumentation in learning contexts of higher education. Afterwards, the data corpus of the research and the analytical approach adopted for the analyses will be presented, thus providing the methodological and conceptual frame on which the present study is based. Two exemplary argumentative sequences that bring to light the results obtained through the observation of a larger corpus of data will be presented and analyzed. A final discussion will open a space for implications and concluding remarks about the use of arguments from expert opinion in the learning context considered for the present study.

\section{Argumentation studies in learning contexts of higher education}

\footnotetext{
${ }^{1}$ Walton (1997) proposes an argument scheme and associated critical questions in order to assess whether or not a certain argument from authority (appeal to authority in Walton's terms) is fallacious.
} 
Over the last two decades, the attention of several educationalists and psychologists has been more and more dedicated to investigating the conditions which can favor or disfavor the creation of effective argumentative activities at a primary and middle school level (Baker, 2002; Duschl and Osborne, 2002; Jackson, 2002; Jiménez-Aleixandre, 2007; Nestlog, 2009; Sadler, 2006), to establish which criteria must be included in assessing the argumentative skills of pupils and students (Anderson et al., 1997; Muller Mirza et al., 2009; Pontecorvo and Girardet, 1993), and how to further improve these skills (Dolz, 1996; Kuhn and Udell, 2003; Nussbaum and Schraw, 2007; Osborne et al., 2004; Zohar and Nemet, 2002).

Despite fewer in number, the studies focusing on the argumentative practices in higher education too have brought to light relevant insights in the fields of education and argumentation theory. In particular, two main lines of research need to be distinguished within these studies. The first line of research aims to single out the cognitive skills that can be improved through argumentative practices in the classroom. Overall, the results of these studies indicate that favoring argument debates in the classroom can enhance students' motivation and engagement (Bova, 2015a; Chin and Osborne, 2010; Hatano and Inagaki, 2003), and help them detect and resolve errors (Schwarz et al., 2000). A series of other studies have also shown that engagement in constructing arguments enhances students' knowledge by promoting conceptual change (e.g., Bova, 2015b; Nussbaum and Sinatra, 2003; Wiley and Voss, 1999), and that the engagement in argumentative small- or large-group discussions improves conceptual understanding (Andrews, 2009; Alexopoulou and Driver, 1996; Mason, 1996, 2001).

The second line of research aims at investigating students' argumentative skills, and how such skills can favor or disfavor the learning process. In this respect, the role of argumentation in the academic context is currently stressed by a growing literature that emphasizes how students rarely use criteria that are consistent with the standards of the scientific community to determine which ideas to accept, reject, or modify. For example, the works of Hogan and Maglienti (2001) and Linn and Eylon (2006) suggest that students often rely on inappropriate criteria such as the teacher's authority or consistency with their personal beliefs to evaluate the merits of a scientific explanation. These researches suggest that students rarely use criteria based on theories and scientific models. Other research suggests that students often do not use sufficient evidence (Sandoval and Millwood, 2005) or struggle to understand what counts as evidence (Sadler, 2004). Moreover, McNeill and Krajcik (2007) found that if students are confronted with large amounts of data, they often encounter difficulties differentiating between what is relevant and what is irrelevant.

Within the research strand on students' argumentative skills, a series of studies devoted attention to the problem of constructing students' knowledge, taking into account their previous beliefs (Arcidiacono and Bova, 2015; Bova, 2015c; Jiménez-Aleixandre et al., 2000; Kelly and Takao, 2002; Macagno and Konstantinidou, 2013; Sampson and Clark, 2008). For instance, Alexander, Kulikowich, and Schulze (1994) have shown that previous knowledge in the domain is a significant predictor of comprehension of the arguments advanced in support of a scientific theory. In a case study analysis of argumentative discourse among high school science students, von Aufschnaiter et al. (2008) suggest that the quality of argumentation itself is mediated by students' prior knowledge and familiarity with the content. Thus, high-level argument requires high-level knowledge of the content. According to the authors, students can engage effectively in argumentation only on content and levels of abstraction that are familiar to them. In the same vein, Sadler and Zeidler (2005) investigated the significance of prior knowledge of genetics for the argumentation of 15 undergraduate students on six cloning scenarios. The findings of this study indicated that students with more advanced genetics understanding demonstrated fewer instances of reasoning flaws, such as lack of coherence and contradiction of reasoning within and between scenarios, and were more likely to incorporate content knowledge in their argumentation than students with more a naïve understanding of genetics.

Taken together, despite differences in methodology and interpretation, the studies on the 
argumentative skills of students in the learning contexts of higher education show to what extent students are able to understand and generate an argument, and to construct justifications in defense of an opinion. However, the results of these studies have also indicated that students often do not base their decisions to accept or reject an idea on available evidence and appropriate reasoning. Rather, they tend to use inappropriate reasoning strategies to warrant one particular view over another and distort, trivialize, or ignore evidence in an effort to reaffirm their own ideas. The present study, which sets out to investigate the types of source on which graduate students in Developmental Psychology base the arguments from expert opinion when used to convince their teacher and classmates to accept their standpoint during disciplinary discussions in the classroom, i.e., task-related discussions concerning the discipline taught in the course, intends to provide an innovative contribution in this field of works related to student-generated arguments in the learning contexts of higher education.

\section{Methodology}

\section{Data Corpus}

The data corpus is composed of sixteen video-recorded separate lessons (constituting about 24 hours of video data) of the Master's degree program Development and Socialization in Childhood and Adolescence at the Utrecht University (The Netherlands). The length of each recording varies from 84 to 98 minutes. The corpus is constituted by 16 students, who were all girls. Most of the students at the time of data collection were in their early 20s $(\mathrm{M}=23.00 ; \mathrm{SD}=1.60)$. As for the student's nationality, the corpus was in large part composed from Dutch students $(\mathrm{N}=12)$, and from only 4 students coming from abroad: 1 from Serbia, 1 from United States, 1 from France, and 1 from Spain.

\section{Students' level of knowledge of the discipline}

Before starting the first lesson of the course (December 2013), students were asked by their teacher (i) to rate in a scale from 1 (none) to 9 (excellent) their own ability to communicate in English language, (ii) if they had already took an academic course in Developmental Psychology, and (iii) to rate in a scale from 1 (none) to 9 (excellent) the level of their previous knowledge in Developmental Psychology, i.e., before taking the course (see Appendix A). As for the ability to communicate in English language, in a scale from 1 to 9 the average score of the graduate students was $\mathrm{M}=7.56$. The most part of the students did already take an academic course in Developmental Psychology (Yes $\mathrm{N}=15$; No $\mathrm{N}=1$ ). In regard to the level of their previous knowledge of the discipline taught in the course, in a scale from 1 to 9 the average score of the students, according to their own perception, was $\mathrm{M}=7.25$.

\section{Data collection and transcription procedures}

Sixteen lessons over a fifteen-week period during the Fall 2013 semester were videotaped. Each lesson lasted about 1 hour 15 minutes. The lessons were typical of the degree courses as a whole since the students were not asked to read materials before the lessons. Most of the time the teacher used a direct teaching method. However, sometimes the students were asked to work cooperatively together using student-centered and inquiry-based learning.

In order to capture the interactions between students and teacher and among students, the whole classroom was videotaped by placing one camera in a back-side corner of the classroom. Each lesson was recorded in its entirety. To minimize researcher interference, the researcher was not 
present into the classroom during the lessons, since he fixed the cameras before starting the lesson and returned to the classroom only once that the students have left the classroom. This means that lessons are documented as they naturally happen, without the researcher imposing tasks or topics, orchestrating the spatial positioning of participants, or affecting the setting of the interaction.

All lessons have been transcribed following with the CHILDES standard transcription system $^{2}$ (CHAT) (MacWhinney, 2000), with some modifications introduced to enhance readability (see Appendix B), and revised by two researchers until a high level of consent has been reached. The level of agreement between the two researchers, as measured by Cronbach's alpha, was very high (.83). In all examples, discursive turns are numbered progressively within the sequence, and participants are identified by role for the teacher (e.g., TEACH) and by role, number, and gender for student (e.g., STU1M, STU2F, STU3F, etc.). In order to ensure the anonymity of students, their names in the paper are pseudonyms.

\section{Ethical Issues}

All participants were approached by means of an information sheet outlining in clear language the general purpose of the study and providing information about how the video data would be used (see Appendix C). Consent letters have been written in accordance with Dutch Association of Psychologists (NIP) and American Psychological Association (APA) guidelines, specifically, the format outlined in the fifth edition of the Publication Manual of the American Psychological Association (APA, 2009) (see Appendix D). In line with the ethical framework guiding the research, the students were assured that their anonymity would be maintained at all stages of the study. Transcriptions and video-recorded material have been treated in the strictest confidence and seen only by researchers.

\section{Definition of argumentative discussion}

The analyses we present in this paper are limited to and focused on the study of analytically relevant argumentative moves, i.e., "those speech acts that (at least potentially) play a role in the process of resolving a difference of opinion" (van Eemeren and Grootendorst, 2004: 73). In particular, only the discussions that fulfill two of the following three criteria, one between i.a and $i . b$ and always the $i i$., were considered as argumentative and selected for analysis, while all nonargumentative conversations were excluded:

i.a at least one standpoint concerning an issue related to the discipline taught in the course put forth by one or more students is questioned - either by means of a clear disagreement or by means of a doubt - by the teacher or by (at least) one classmate, e.g. STU1: I think that Piaget's notion that children's development must necessarily precede their learning is wrong STU2: No, I think that Piaget was right.

i.b at least one standpoint concerning an issue related to the discipline taught in the course put forth by the teacher is questioned - either by means of a clear disagreement or by means of a doubt - by one or more students, e.g. TEACH: During this phase ((adolescence)) they ((adolescents)) have to decide their goals and values for their future - STU6: Some adolescents decide not to choose though.

\footnotetext{
2 The CHAT system provides a standardized format for producing computerized transcripts of face-to-face conversational interactions for the Child Language Data Exchange System (CHILDES). The system provides options for basic discourse transcription as well as detailed phonological and morphological analyses. Verbal utterances and nonverbal expressions with a clear communicative function relevant to the meal activity were identified in the transcription.
} 
ii. at least one student advances at least one argument either in favor of or against the standpoint being questioned, e.g. STU1: Some adolescents decide not to choose though, according to Marcia it's the identity diffusion, they are not ready to take these decisions.

\section{Identification of the arguments}

After having selected all the argumentative discussions that occurred in the corpus of sixteen videorecorded separate lessons, we selected all the argumentative discussions in which students put forward arguments from expert opinion. As we stated in the Introduction section, in the present study we refer to the definition of argument from expert opinion as the notion of epistemic authority elaborated by Walton (1997: 77-78), with no intention of dealing with the notion of deontic authority:

The epistemic authority is a relationship between two individuals where one is an expert in a field of knowledge in such a manner that his pronouncements in this field carry a special weight of presumption for the other individual that is greater than the say-so of a layperson in that field. The epistemic type of authority, when used or appealed to in argument, is essentially an appeal to expertise, or to expert opinion. By contrast, the deontic type of authority is a right to exercise command or to influence, especially concerning rulings on what should be done in certain types of situations, based on an invested office, or an official or recognized position of power ${ }^{3}$.

The criteria in order to select the arguments from expert opinion used by students during disciplinary discussions in the classroom has been based on the definition of epistemic authority elaborated by Walton. It can be described trough the following statement: "Person X said/did Y, therefore Y must be right/accepted". The data set in the present study is composed of $\mathrm{N}=66$ arguments from expert opinion which meet the criteria outlined above.

\section{Analytical approaches}

The pragma-dialectical ideal model of critical discussion and the Argumentum Model of Topics represent the analytical approaches in order to identify and analyze the argumentatively relevant moves and to systematically reconstruct the inferential configuration of arguments, respectively. Both these approaches will be briefly introduced below.

\section{The model of a critical discussion}

The theoretical tool adopted for the selection of argumentative discussions from the corpus is the pragma-dialectical ideal model of a critical discussion (van Eemeren and Grootendorst, 2004). This approach considers that argumentative speech acts are not performed in a social vacuum, but between two or more parties who are having a disagreement and interact with each other in an attempt to resolve this disagreement. As suggested by van Eemeren and Houtlosser (2003), to transcend a merely descriptive stance in studying argumentation, the focus is on the explication of

\footnotetext{
${ }^{3}$ The italics are not in the original text of Walton.
} 
the critical standards to which arguers appeal when engaging in a regulated process of resolving a difference of opinions. The pragma-dialectical approach to argumentation proposes the model of a critical discussion as an ideal definition of argumentation, because it does not aim to describe how argumentative discourse occur in reality but how it would be structured were such discourse to be solely aimed at resolving differences of opinion: "To some degree, real-life argumentative discourse will always deviate from the ideal model" (van Eemeren and Grootendorst, 1992: 35).

The model of a critical discussion spells out four stages that are necessary for a dialectical resolution of differences of opinion (ibid. p.35; see also van Eemeren and Grootendorst, 2004: 6061):

- Confrontation stage. It is in the confrontation stage that the two parties establish the existence of a dispute. A standpoint is advanced and questioned.

- Opening stage. At the opening stage, the decision is made to attempt to resolve the dispute by means of an argumentative discussion. One party takes the role of protagonist, which means that $\mathrm{s} / \mathrm{he}$ is prepared to defend the standpoint through argumentation; the other party takes the role of antagonist, which means that s/he is prepared to challenge the protagonist systematically to defend the standpoint.

- Argumentation stage. At the argumentation stage, the protagonist defends a standpoint and the antagonist elicits further argumentation in the case that there are further doubts.

- Concluding stage. At the concluding stage, the parties establish whether the dispute has been resolved through retraction of either the standpoint or the doubt concerning the standpoint.

This model is assumed, in the present study, as a grid for the analysis, since it provides the criteria for the selection of the argumentative discussions between student and teacher and among students.

\section{The Argumentum Model of Topics}

The AMT is a model that serves to systematically reconstruct the inferential configuration of arguments, that is, "to illustrate the structure of reasoning that underlies the connection between a standpoint and its supporting arguments" (Rigotti and Greco Morasso, 2010: 490). The general principle underlying the reconstruction of the inferential configuration of an argumentative move is that of finding the implicit premises on which the argument is based.

According to Rigotti and Greco Morasso (2010: 493-502), who elaborated this theoretical tool, two fundamental components should be distinguished when identifying the inferential relation binding the premises to the conclusion of argumentation. First, an argument identifies a topical component which focuses on the inferential connection activated by the argument corresponding to the abstract reasoning that justifies the passage from the premises (arguments) to the conclusion (standpoint). The inferential connection underlying the argument is named with the traditional term maxim. Maxims are inferential connections generated by a certain semantic ontological domain named locus ${ }^{4}$. Second, an endoxical component, which consists of the implicit or explicit material premises shared by the discussants that, combined with the topical component, grounds the standpoint. These premises include endoxa, which include general principles, values, and assumptions that typically belong to the specific context, and data, which consists of facts or other information regarding the specific situation at hand and include the part of the argument that is made explicit in the text.

Despite its particular concern for the inferential aspects of argumentation, the AMT, de facto,

\footnotetext{
${ }^{4}$ For a comprehensive presentation of the taxonomy of loci, see Rigotti (2009: 166-168) and Greco Morasso (2011: 127-129).
} 
accounts not only for the logical aspects of the argumentative exchange (topical component), but also for its embeddedness in the parties' relationship (endoxical component), and thus proves to be particularly suited for the argumentative analysis of student-teacher and student-student conversations in the classroom.

\section{Results}

Overall, the students advanced at least one argument from expert opinion in $\mathrm{N}=52$ discussions, for a total number of $\mathrm{N}=66$ arguments from expert opinion. These arguments were in most cases advanced during student to student interactions $(\mathrm{N}=4873 \%)$, while a fewer number of arguments were observed during student-teacher interactions $(\mathrm{N}=18 ; 27 \%)$. What first emerges from the analyses of the arguments from expert opinion used by graduate students during disciplinary discussions in the classroom is that students in most cases $(n=51 ; 78 \%)$ used the argument from expert opinion as other-oriented arguments, i.e., arguments in which they refer to scientific notions and theories strictly or somehow related to the discipline taught in the course as source of expertise Less frequently $(\mathrm{n}=15 ; 22 \%)$, instead, the students used the argument from expert opinion as selforiented arguments, i.e., arguments in which they refer to their previous personal experience as source of expertise. In the corpus, we did not observe any significant difference between the types of arguments (other-oriented vs. self-oriented) used in student-student interactions and studentteacher interactions.

In discussing the results, we will present the analysis of two case studies representative of the results obtained from the larger set of analyses conducted on the whole corpus of $\mathrm{N}=66$ arguments from expert opinion used by students. The first example presented and discussed here shows how a student refers to a scientific theory, i.e., the Kohlberg's theory of moral development (Kohlberg, 1984), as source of expertise (other-oriented argument). The second example shows how a student refers to herself and her own personal experience as source of expertise (self-oriented argument).

\section{Analysis of two case studies}

\section{Example 1}

Lesson 4. Min. 59:50. Participants: teacher (TEACH), student (STU6M).

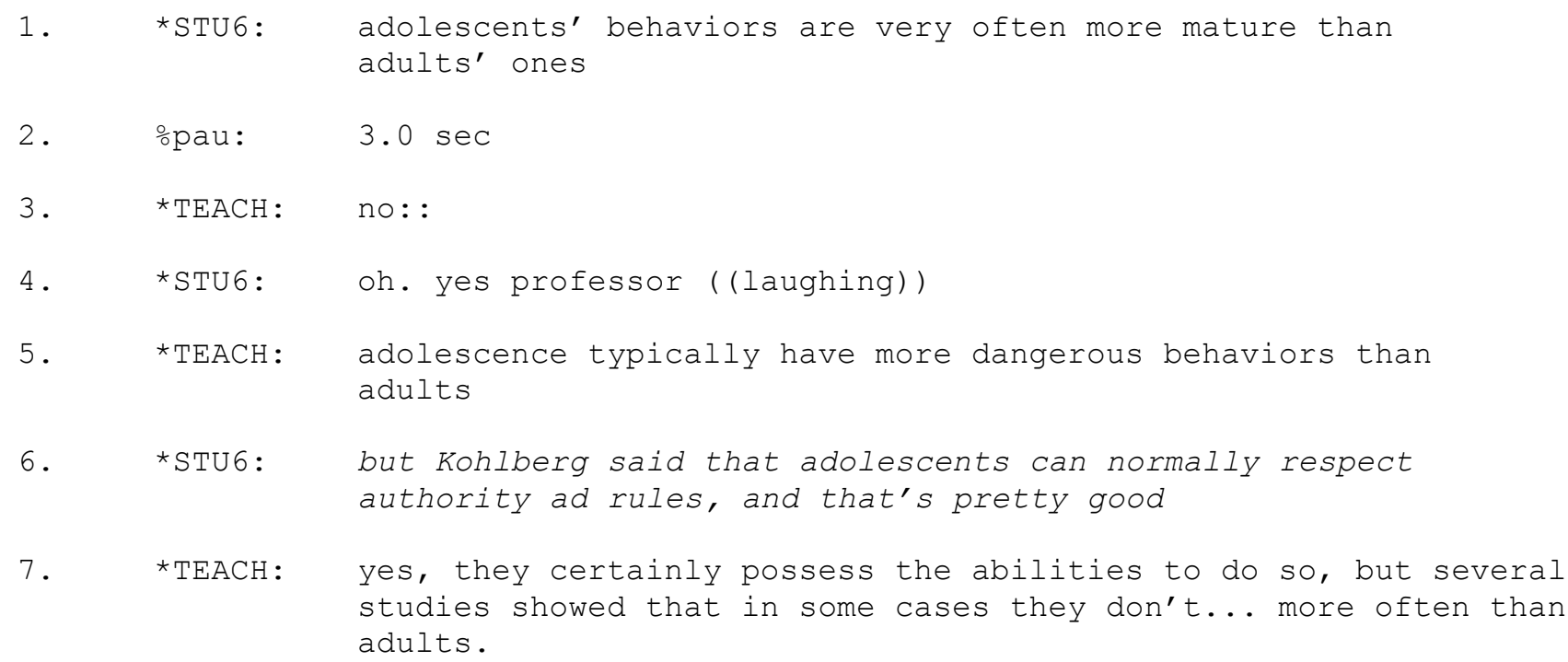


In example 1 we can observe that the teacher and the students are discussing about a wellknown topic in the of field of Developmental Psychology, namely, the moral development in adolescence. In particular, it is possible to observe the following difference of opinion between the teacher and a student (STU6): according to the student, adolescents' behaviors show to be very often more mature than adults' ones, while the teacher clearly disagrees with her student's opinion (line 3: "no::") and puts forth an argument in support of her standpoint (line 5: "adolescence typically have more dangerous behaviors than adults"). In turn, the student advances an argument from expert opinion (in Italic in the excerpt) that refers to the well-known Kohlberg's theory of moral development in order to support her own standpoint (line 6: "but Kohlberg said that adolescents can normally respect authority ad rules, and that's pretty good"). In line 7, the teacher clearly manifests her disagreement with her student, and puts forth another argument in support of her own standpoint. This discussion will continue for several minutes, involving other students as well.

The analytical overview of this discussion is summarized below, in Table 1:

Table 1: Analytical overview of the example (1)

\begin{tabular}{|l|l|}
\hline Standpoint(s) & $\begin{array}{l}\text { (STU6) Adolescents' behaviors are not more dangerous than adults' ones } \\
\text { (TEACH) Adolescents' behaviors are more dangerous than adults' ones }\end{array}$ \\
\hline Student's argument & 1. Kohlberg said that adolescents can normally respect authority ad rules \\
\hline
\end{tabular}

In the analysis of this argumentative discussion, we will focus on the argument put forth by the student in line 6: Kohlberg said that adolescents can normally respect authority ad rules. The Ystructure (so-called because its form looks like the letter Y) in Figure 1 will be the graphical tool adopted for representing the AMT's reconstruction. Instances of applications of the AMT's reconstructions by using the Y-structure can be found in several studies devoted to argumentation in various contexts (see e.g., Bova 2015d, 2015e; Greco Morasso, 2012; Palmieri, 2009; Pollaroli and Rocci, 2015): 


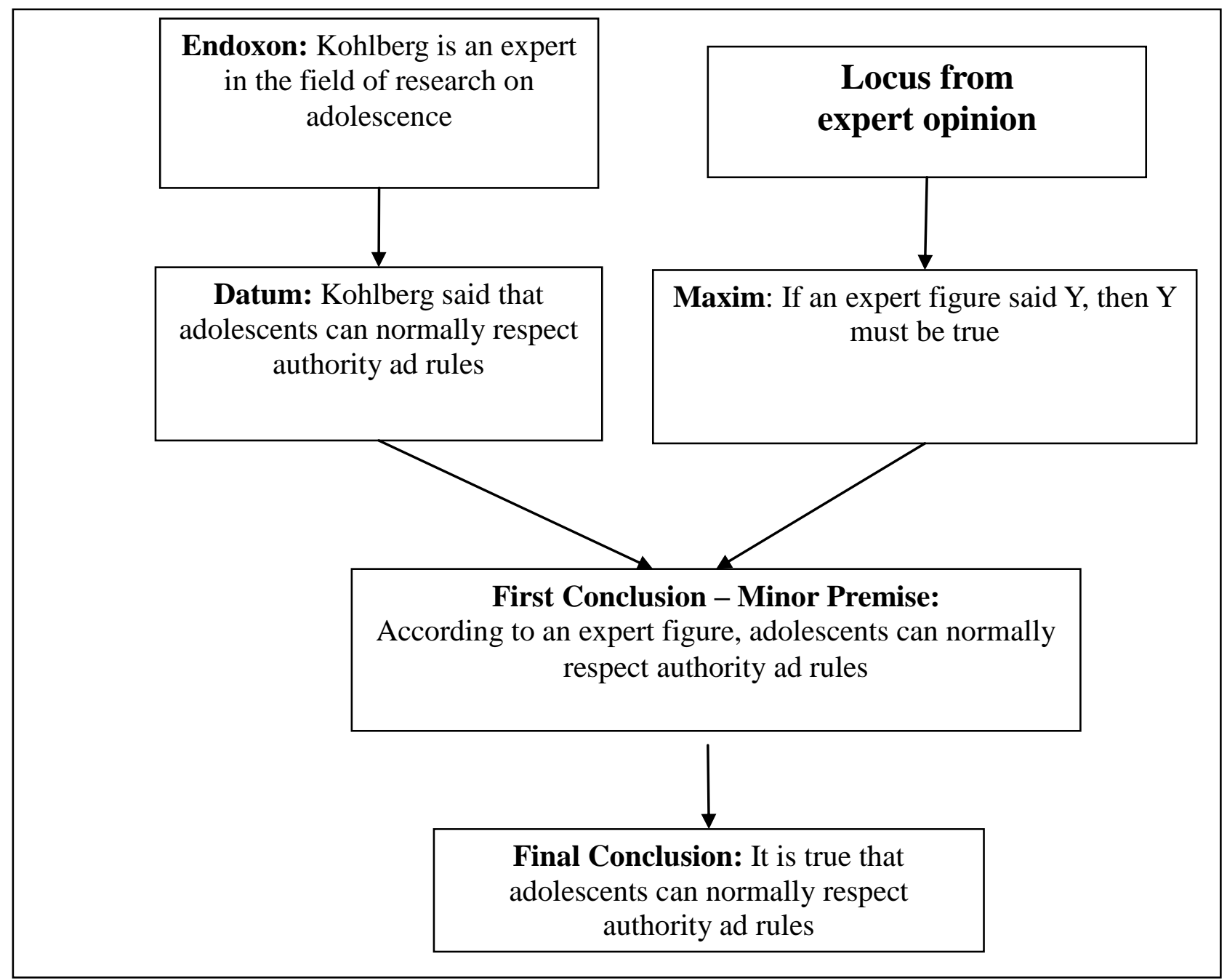

Figure 1: AMT-based reconstruction of the student's argument from expert opinion (example 1)

This argument is based on a maxim that is engendered from the locus from expert opinion: "If an expert figure said $\mathrm{Y}$, then $\mathrm{Y}$ must be true". The reasoning follows with a syllogistic, i.e. inferential, structure, "According to an expert figure, adolescents can normally respect authority ad rules" (minor premise), which brings to the conclusion that "It is true that adolescents can normally respect authority ad rules". However, this is only one part of the argumentation. The fact that "According to an expert figure, adolescents can normally respect authority ad rules" needs further justifications; unlike the maxim, this is not an inferential rule but a factual statement that must be backed by contextual knowledge. Looking at the endoxical syllogism of the diagram, the endoxon is the following: "Kohlberg is an expert in the field of research on adolescence". The datum, "Kohlberg said that adolescents can normally respect authority ad rules", combined with the endoxon lead to the first conclusion that "According to an expert figure, adolescents can normally respect authority ad rules".

The AMT-reconstruction shows that the student refers to an important scholar, i.e., Lawrence Kohlberg, to convince her teacher and classmates to accept her own standpoint. However, this argument is not effective in convincing the teacher to change her stance. One may ask why this has occurred. In order to answer this question, the reconstruction trough the AMT comes to help us. In fact, looking at the final conclusion of this argument ("It is true that adolescents can normally respect authority ad rules"), we can observe that the student is not making any comparison between adults and adolescents, but she is only referring to the adolescents' behavior. Now, the fact that adolescents can normally respect authority ad rules, does not necessarily mean that their behaviors are more mature than adults' ones.

In the corpus of 66 arguments from expert opinion considered for the present study, the 
students referred less frequently to themselves and their own personal experience as source of expertise $(\mathrm{N}=15 ; 22 \%)$. This type of use of the argument from expert opinion by students is clearly illustrated in the following example, where a student refers to herself and her personal opinion to convince her classmates that not all mental disorders are determined by having a predisposition. In this case, the argument put forth by the student appears more effective than the one analyzed in the previous example where the expert was an important scholar.

\section{Example 2}

Lesson 2. Min. 24:30. Participants: teacher (TEACH), students (STU15F; STU1F).

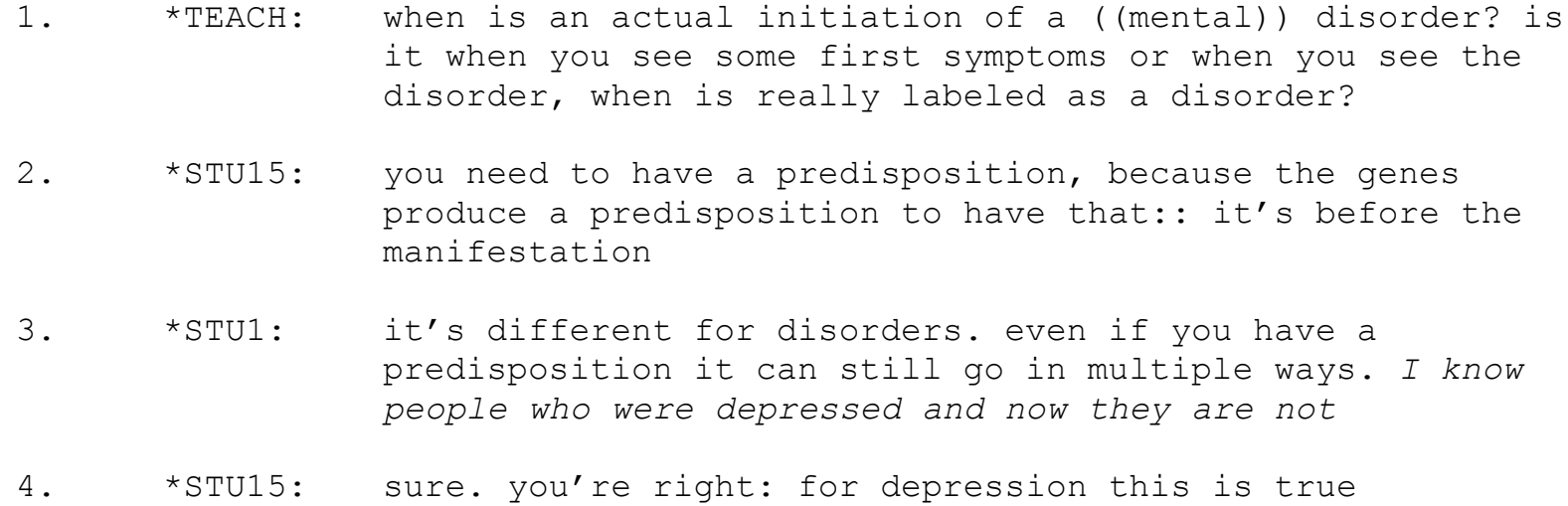

In example 2, the beginning of a discussion about mental disorders in adolescence and the moment of their actual initiation is favored by the teacher. Here, it is possible to observe an argumentative discussion initially involving two students: STU15 and STU1. According to the first student, the actual initiation of a mental disorder is before the manifestation, and she supports her opinion by advancing an argument based on common sense knowledge (line 2: "you need to have a predisposition, because the genes produce a predisposition to have that:: it's before the manifestation"). The second student disagrees with the first student's opinion, because according to her having a predisposition is fundamental only for certain mental disorders, but not for all of them. In particular, she supports this claim by also advancing an argument that is based on her own personal experience (in Italic in the excerpt) (line 3: "I know people who were depressed and now they are not"). In line 4, the student STU15 shows to accept the argument put forth by her classmate (line 4: "sure. you're right: for depression this is true"). This discussion will continue for several minutes, involving other students that have different opinions as well as the teacher.

The analytical overview of this discussion is summarized below, in Table 2:

Table 2: Analytical overview of the example (2)

\begin{tabular}{|l|l|}
\hline Standpoint(s) & $\begin{array}{l}\text { (STU1) Not all the mental disorders are determined by having a predisposition } \\
\text { (STU15) All the mental disorders are determined by having a predisposition }\end{array}$ \\
\hline $\begin{array}{l}\text { Student's argument } \\
\text { (STU1) }\end{array}$ & 1. I know people who were depressed and now they are not \\
\hline
\end{tabular}

In the analysis of this argumentative discussion, we will focus on the argument put forth by the student in line 3: I know people who were depressed and now they are not. The reconstruction of its inferential configuration is illustrated below, in Figure 2: 


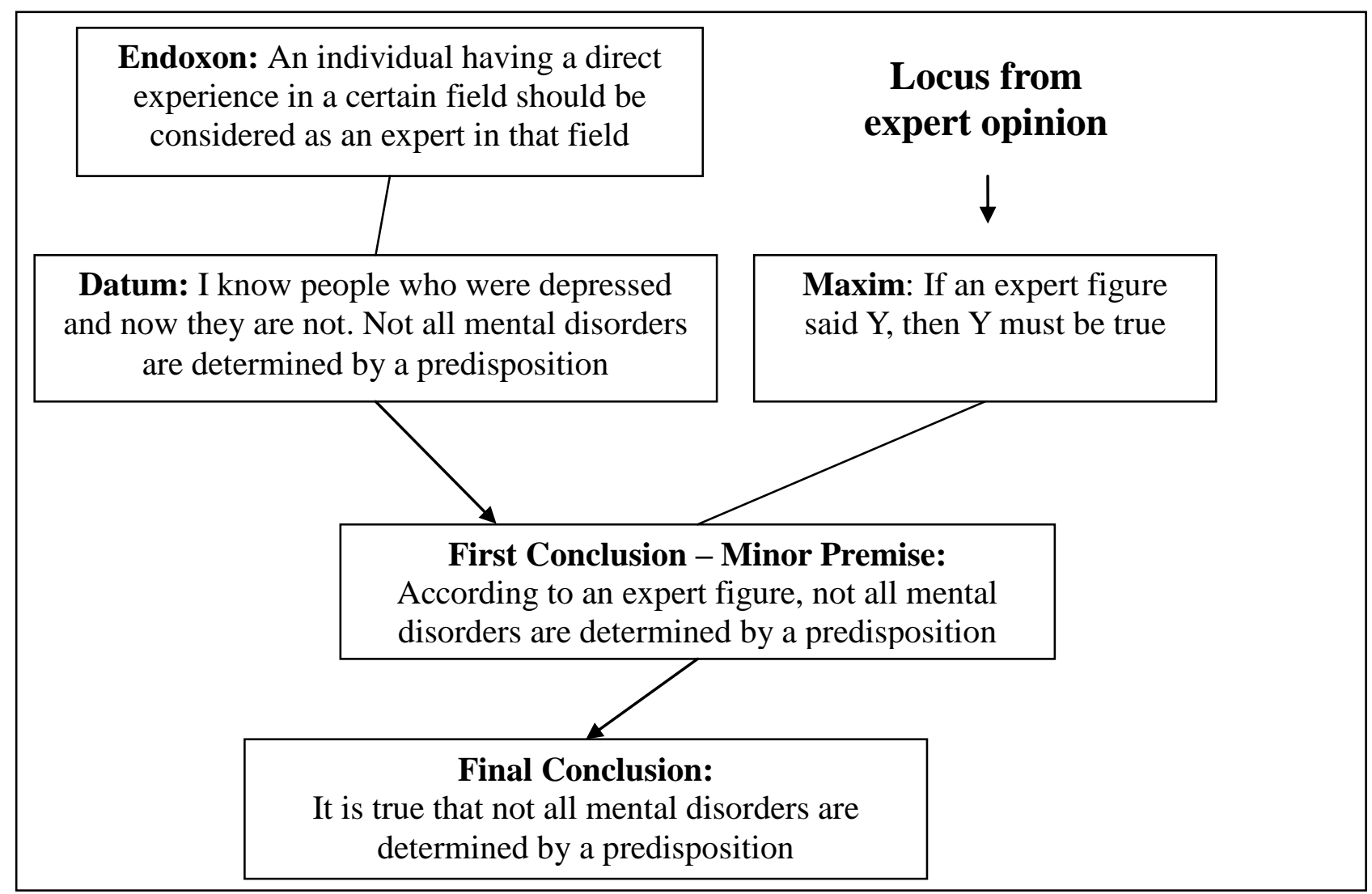

Figure 2: AMT-based reconstruction of the student's argument from expert opinion (example 2)

On the right-hand side of the diagram the maxim engendered from the locus from expert opinion on which the mother's argument is based is specified: "If an expert figure said Y, then Y must be true". The minor premise of the topical syllogism is that "According to an expert figure, not all mental disorders are determined by a predisposition", which combined with the maxim brings to the following final conclusion: "It is true that not all mental disorders are determined by a predisposition". Looking at the endoxical dimension of the diagram, in this argument the endoxon is as follows: "An individual having a direct experience in a certain field should be considered as an expert in that field". The datum of the endoxical dimension (I know people who were depressed and now they are not. Not all mental disorders are determined by a predisposition) combined with the endoxon, produces the first conclusion that "According to an expert figure, not all mental disorders are determined by a predisposition". In our opinion, the fact that the students knows people who were depressed and now they are not implies that this students have had a direct experience in this field and, accordingly, she should be considered as an expert in that field.

The AMT-reconstruction shows that the student refers to herself and her personal experience as source of expertise to convince her classmate to accept her standpoint. Unlike the previous example, the second student accepts the argument put forth by her classmate and changes her stance. Looking at the reaction by the second student (STU15: "sure. you're right: for depression this is true"), in this second example the endoxon on which the argument put forward by the student is based on (An individual having a direct experience in a certain field should be considered as an expert in that field) is not put into doubt by the other discussant.

This last case study shows how students can use the argument from expert opinion referring to themselves (self-oriented argument), and not only to scholars and their scientific theories and notions (other-oriented argument). Interestingly, in our corpus the self-oriented arguments from expert opinion had a greater effectiveness than the other-oriented arguments from expert opinion. When the students referred to a scholar and his/her theories as source of expertise, the other students accepted their standpoint in less than half of the cases (23 out of 51; 45\%). Instead, when the students referred to them-selves and their personal experiences, the other students accepted their 
standpoint more than half of the cases (11 out of $15 ; 73 \%)$. Because the study of a small number of conversations does not permit conclusions of general order, further investigation in this direction is certainly necessary.

\section{Discussion}

In order to provide a further contribution to the study of argumentative practices in the learning contexts, this study examined the argumentative disciplinary discussions in the classroom, i.e., taskrelated argumentative discussions concerning the discipline taught in the course, with the aim to investigate the types of source on which students base the arguments from expert opinion when used to convince their teacher and classmates to accept their standpoint. The model of a critical discussion and the Argumentum Model of Topics have allowed a possibility to observe how participants use arguments from expert opinion. The analyses have shown that students in most cases $(n=51 ; 78 \%)$ used the argument from expert opinion as other-oriented arguments, i.e., arguments in which they refer to scientific notions and theories strictly or somehow related to the discipline taught in the course as source of expertise. Less frequently $(n=15 ; 22 \%)$, instead, the students used the argument from expert opinion as self-oriented arguments, i.e., arguments in which they refer to their previous personal experience as source of expertise. In light of these results, it is reasonable to assume that for the student, in their own perception, the reference to scholars and scientific notions and theories is a more valid, i.e. convincing, argument than the reference to themselves and their own personal experience. However, the findings of this study do not seem to confirm the greater validity of the other-oriented argument from expert opinion; rather we observed that when the students refer to their own previous personal experience as source of expertise they are able to convince their teacher and classmates of the validity of their opinion.

How do these results relate to actual crucial questions involving the argumentative discussion in the classroom? From an argumentative perspective, favoring argumentative discussions in the classroom allows students to be active participants in the process of construction of new knowledge, and not only listeners (Baker, 2009). In agreement with other scholars (Duschl and Osborne, 2002; Erduran and Jiménez-Aleixandre, 2007; Ford, 2008; López-Facal et al., 2015; Kuhn, 1993; Newton et al., 1999), if students are not empowered to criticize the ideas being discussed then they must accept the ideas that sound plausible and/or are held by the individual with the most influence. In this regard, the literature has already demonstrated that discussing about a certain topic is more effective than only listening it (Chin and Osborne, 2010; Nussbaum and Sinatra, 2003; Schwarz et al., 2000; Means and Voss, 1999). In the present study, we have seen that the students are able to engage in disciplinary argumentative discussions and to use, at times, complex arguments in support of their standpoints. Accordingly, creating situations in which it makes sense for students to freely engage with one another's ideas is crucial for the development of their argumentative skills. Teaching argumentation and learning via argumentation is an important shared goal in educational settings. In particular, the capacity to understand the processes underlying argumentative reasoning represents the starting point for a conscious and critical acquisition by students of the scientific knowledge co-constructed - at all levels - in learning contexts.

This study intended to explore ways of scaffolding students' argumentation in learning contexts of higher education: the results provide relevant insights and systematic data to instructional designers interested in planning argumentative protocols aimed at enriching the critical level of students at the graduate level. The findings shed also light on theoretical aspects that have scarcely been investigated in current argumentation studies, namely, the logical properties and the premises on which students' arguments are based. The analysis of these aspects can play an important role in the analysis and evaluation of students' argumentative skills. In relation to the reconstruction of implicit premises in the process of argumentation, the integration of the ideal 
model of a critical discussion with the Argumentum Model of Topics opens radically new perspectives for the study of students' argumentation in the learning contexts of higher education responding to a need emerged from literature. Although the combination of these two tools of analysis has already proven fruitful in previous studies devoted to various spheres of activities (Bova and Arcidiacono, 2013; Greco Morasso, 2011; Palmieri, 2014), the application to studies on students' argumentation undoubtedly represents a great challenge for scholars interested in learning contexts.

\section{Acknowledgements}

The Swiss National Science Foundation under Grant number P2TIP1_148347 supported this work.

\section{Appendices}

\section{Appendix A: Teacher-student dialogue in the academic context}

This project will investigate dialogues between students and professors during university lessons. The dialogues will be video and audio recorded. The recordings will, in first instance, be transcribed and analyzed. These recordings will not be shown to the general public.

Below are few questions. Please fill in the appropriate square for questions 1-7. Please DO NOT WRITE YOUR NAME ON THE QUESTIONNAIRE AS THIS STUDY IS ANONYMOUS. Do not feel obligated to answer all questions if you are uncomfortable or unable to do so. Thank you very much for taking the time to complete the present questionnaire, your effort is greatly appreciated.

Please contact me if you require further information about the project, or to have any questions answered. Thank you for taking the time to read this information.

Your with best wishes,

$\operatorname{Xxxxxxxx} \operatorname{Xxx} \operatorname{xxxxx}$

Date: $\quad$ December 10, 2013

Telephone: $03025 \mathrm{X}$ XX XX

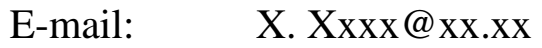

Please answer the following questions:

1. Are you a girl or a boy?

Girl $\quad$ Boy

2. When were you born?
a) Month
b) Year

January 
April

May

June

July

August

September

October

November

December
1988

1989

1990

1991

1992

1993

1994

1995

Other $19 \ldots$.

3. Where were you born?

The Netherlands

Other

4. What is your first language?

$$
\text { English }
$$

Non-English

5. Rate your ability to communicate in English

$$
\begin{array}{lllllllllll}
\text { None } & 1 & 2 & 3 & 4 & 5 & 6 & 7 & 8 & 9 & \text { Excellent }
\end{array}
$$

6. In your previous study experience, did you already take an academic course in developmental psychology?

$$
\text { Yes } \square \quad \text { No }
$$

7. Rate your knowledge in developmental psychology before the beginning of this course

$$
\begin{array}{lllllllllll}
\text { None } & 1 & 2 & 3 & 4 & 5 & 6 & 7 & 8 & 9 & \text { Excellent }
\end{array}
$$

\section{Appendix B: Transcription symbols}

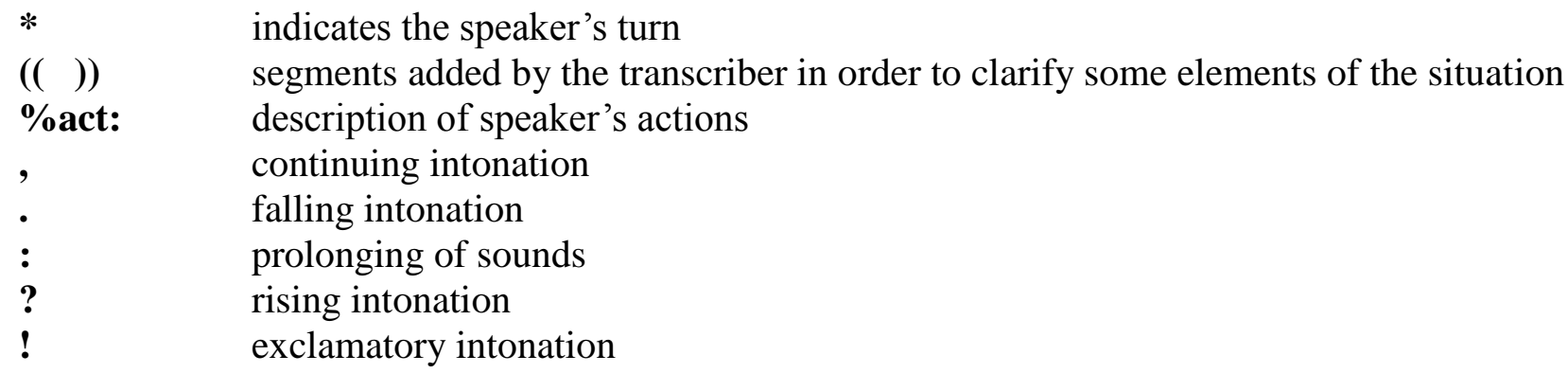

\section{Appendix C: Information sheet}

This project will investigate dialogues between students and professors during university lessons. The dialogues will be video and audio recorded. The recordings will, in first instance, be transcribed and analyzed. These recordings will not be shown to the general public, but short excerpts maybe used for educational purposes. 
If you have concerns about your anonymity being maintained, you may ask for your faces to be blurred. Individual information and data obtained are not accessible to third parties outside our research group. You may retain this information sheet for reference. Please feel free to ask any questions you may have before completing the consent form (which will be stored separately from the anonymous information you provide for the research project).

Please contact me if you require further information about the project, or to have any questions answered. Thank you for taking the time to read this information.

Your with best wishes,

$\operatorname{Xxxxxxx} \operatorname{Xxxxxxx}$

Telephone: $\quad 030$ 25X XX XX

E-mail: $\quad$ X.Xxxxxx@xx.xx

\section{Appendix D: Consent form}

I consent to $\mathrm{Xxxxxx}$ Xxxx carrying out the following:

1. recording (audio-video) lessons on approximately 8 occasions over a two-months period;

2. transcribing and analyzing the recordings of lessons;

3. using short recorded excerpts for educational purposes.

I have received an information sheet explaining the general purpose of the study and of the opportunity to ask further questions and with the assurance that the rights to my privacy and confidentiality will be respected at all times.

Signed:

Date

\section{References}

Alexander, P. A., Kulikowich, J. M., \& Schulze, S. K. (1994). The influence of topic knowledge, domain knowledge, and interest on the comprehension of scientific exposition. Learning and Individual Differences, 6(4), 379-397.

Alexopoulou, E., \& Driver, R. (1996). Small-group discussion in physics: peer interaction modes in pairs and fours. Journal of Research in Science Teaching, 33(10), 1099-1114.

Anderson, R. C., Chinn, C. A., Chang, J., Waggoner, M., \& Yi, H. (1997). On the logical integrity of children's arguments. Cognition and Instruction, 15(2), 135-167.

Andrews, R. (2009). A case study of argumentation at undergraduate level in History. Argumentation. Special Issue on Argumentation and Education: Studies from England and Scandinavia, 23(4), 547-548. 
Arcidiacono, F., \& Bova, A. (2015). A study of the arguments used by undergraduate and graduate students during disciplinary discussions in the classroom. In R.V. Nata (Ed.), Progress in Education vol. 33 (pp. 31-50). Hauppauge, NY: Nova Science Publishers.

Baker, M. (2002). Argumentative interactions, discursive operations and learning to model in science. In P. Brna, M. Baker, K. Stenning, \& A. Tiberghien (Eds.), The role of communication in learning to model (pp. 303-324). Mahwah, NJ: Lawrence Erlbaum.

Baker, M.J. (2009). Argumentative interactions and the social construction of knowledge. In N. M. Mirza, \& A.-N. Perret-Clermont (Eds.), Argumentation and Education (pp. 127-144). New York: Springer.

Bova, A. (2015a). Favoring argumentative disciplinary discussions in the classroom. A study of teacher's questions at undergraduate and graduate level. Learning, Culture and Social Interaction, 7, 97-108.

Bova, A. (2015b). Promoting learning and development of students through argumentative interactions in the classroom. Teaching Innovations, 28(3), 130-144.

Bova, A. (2015c). A study of undergraduate and graduate students' argumentation in learning contexts of higher education. In B.J. Garssen, D. Godden, G. Mitchell, \& A.F. Snoeck Henkemans (Eds.), Proceedings of the Eighth Conference of the International Society for the Study of Argumentation (pp. 173-185). Amsterdam: Sic Sat.

Bova, A. (2015d). "This is the cheese bought by Grandpa". A study of the arguments from authority used by parents with their children during mealtimes. Journal of Argumentation in Context, $4(2), 133-157$.

Bova, A. (2015e). Adult as a source of expert opinion in child's argumentation during family mealtime conversations. Journal of Argumentation in Context, 4(1), 4-20.

Bova, A., \& Arcidiacono, F. (2013). Invoking the authority of feelings as a strategic maneuver in family mealtime conversations. Journal of Community and Applied Social Psychology, 23(3), 206-224.

Chin, C., \& Osborne, J. (2010). Supporting argumentation through students' questions: Case studies in science classrooms. Journal of the Learning Sciences, 19(2), 230-284.

Dolz, J. (1996). Learning argumentative capacities. A study of the effects of a systematic and intensive teaching of argumentative discourse in 11-12 year old children. Argumentation, 10(2), 227-251.

Duschl, R., \& Osborne, J. (2002). Supporting and promoting argumentation discourse in science education. Studies in Science Education, 38(1), 39-72.

Duschl, R., Schweingruber, H., \& Shouse, A., (2007). Taking science to school: Learning and teaching science in grades $K-8$. Washington, DC : National Academies Press.

van Eemeren F. H., \& Grootendorst, R. (1992). Argumentation, communication, and fallacies. A pragma-dialectical perspective. Hillsdale, NJ: Erlbaum.

van Eemeren, F. H., \& Grootendorst, R. (2004). A systematic theory of argumentation: The pragma-dialectical approach. Cambridge: Cambridge University Press.

van Eemeren, F. H., \& Houtlosser, P. (2003). The development of the Pragma-dialectical approach to argumentation. Argumentation, 17(4), 387-403.

Erduran, S., \& Jiménez-Aleixandre, M. P. (2007). Argumentation in science education: Perspectives from classroom-based research. Dordrecht: Springer.

Ford, M. (2008). Disciplinary authority and accountability in scientific practice and learning. Science Education, 92(3), 404-423.

Hatano, G., \& Inagaki, K. (2003). When is conceptual change intended? A cognitive-sociocultural view. In G. M. Sinatra, \& P. R. Pintrich (Eds.), Intentional conceptual change (pp. 407-427). Mahwah, NJ: Lawrence Erlbaum Associates.

Hogan, K., \& Maglienti, M. (2001). Comparing the epistemological underpinnings of students and scientists reasoning about conclusions. Journal of Research in Science Teaching, 38(6), 663687. 
Greco Morasso, S. (2011). Argumentation in dispute mediation: A reasonable way to handle conflict. Amsterdam: John Benjamins.

Greco Morasso, S. (2012). Contextual frames and their argumentative implications: a case-study in media argumentation. Discourse Studies, 14(2), 197-216.

Jackson, S. (2002). Designing argumentation protocols for the classroom. In F.H. van Eemeren (Ed.), Advances in pragma-dialectics (pp. 105-120). Amsterdam: Sic Sat.

Jiménez-Aleixandre, M. P. (2007). Designing argumentation learning environments. In S. Erduran, \& M. P. Jiménez-Aleixandre (Eds.), Argumentation in science education: Perspectives from classroom-based research (pp. 89-113). Dordrecht: Springer.

Jiménez-Aleixandre, M. P., Rodriguez, A. B., \& Duschl, R. A. (2000). “'Doing the lesson' or “'Doing science': Argument in high school genetics. Science Education, 84(6), 757-792.

Kelly, G. J., \& Chen, C. (1999). The sound of music: Constructing science as sociocultural practices through oral and written discourse. Journal of Research in Science Teaching, 36(8), 883-915.

Kelly, G., \& Takao, A. (2002). Epistemic levels in argument: An analysis of university oceanography students' use of evidence in writing. Science Education, 86(3), 314-342.

Kohlberg, L. (1984). The Psychology of Moral Development: Moral Stages and the Idea of Justice. San Francisco, CA: Harper \& Row.

Kuhn, D. (1993). Science as argument: implications for teaching and learning scientific thinking. Science Education, 77(3), 319-337.

Kuhn, D., \& Udell, W. (2003). The development of argument skills. Child Development, 74(5), 1245-1260.

Linn, M. C., \& Eylon, B. S. (2006). Science education: Integrating views of learning and instruction. In P. A. Alexander, \& P. H. Winne (Eds.), Handbook of Educational Psychology (2nd ed.) (pp. 511-544). Mahwah, NJ: Lawrence Erlbaum Associates.

López-Facal, R., Jiménez-Aleixandre, M. P., \& Arcidiacono, F. (2015). Le territoire comme composante de l'identification nationale dans l'argumentation des élèves du secondaire. In $\mathrm{N}$. Muller Mirza \& C. Buty (Eds.), Argumentation dans les contextes de l'éducation (pp. 323354). Bern: Lang.

Macagno, F., \& Konstantinidou, A. (2013). What students' arguments can tell us: Using argumentation schemes in science education. Argumentation, 27(3), 225-243.

MacWhinney, B. (2000). The child project: Computational tools for analyzing talk. Pittsburgh, PA: Routledge.

Mason, L. (1996). Collaborative reasoning on self-generated analogies. Conceptual growth in understanding scientific phenomena. Educational Research and Evaluation, 2(4), 309-350.

Mason, L. (2001). Introducing talk and writing for conceptual change: a classroom study. Learning and Instruction, 11(6), 305-329.

McNeill, K. L., \& Krajcik, J. (2009). Synergy between teacher practices and curricular scaffolds to support students in using domain specific and domain general knowledge in writing arguments to explain phenomena. Journal of the Learning Sciences, 18(3), 416-460.

Means, M.L., \& Voss, J.F. (1996). Who reason well? Two studies of informal reasoning among children of different grade, ability, and knowledge levels. Cognition and Instruction, 14(2), 139-178.

Muller Mirza, N., \& Perret-Clermont, A.-N., Tartas, V., \& Iannaccone, A. (2009). Psychosocial processes in argumentation. In N. Muller Mirza, \& A.-N. Perret-Clermont (Eds.), Argumentation and education (pp. 67-90). New York, NY: Springer.

Nestlog, E. B. (2009). Witten argumentation by a 10-year-old pupil in Sweden. Argumentation, 23(4), 437-449.

Newton, P., Driver, R., \& Osborne, J. (1999). The place of argument in the pedagogy of school science. International Journal of Science Education, 21(5), 553-576.

Nussbaum, E. M., \& Sinatra, G. M. (2003). Argument and conceptual engagement. Contemporary Educational Psychology, 28(3), 384-395. 
Nussbaum, E. M., \& Schraw, G. (2007). Promoting argument-counterargument integration in students' writing. The Journal of Experimental Education, 76(1), 59-92.

Osborne, J. (2005). The role of argument in science education. In K. Boersma, M. Goedhart, O. de Jong, \& H. Eijkelhof (Eds.), Research and the quality of science education (pp. 367-380). Dordrecht: Springer.

Osborne, J., Erduran, S., \& Simon, S. (2004). Enhancing the quality of argumentation in school science. Journal of Research in Science Teaching, 41(10), 994-1020.

Palmieri, R. (2009). Regaining trust through argumentation in the context of the current financialeconomic crisis. Studies in Communication Sciences, 9(2), 59-78.

Palmieri R. (2014) Corporate argumentation in takeover bids. Amsterdam/Philadelphia: John Benjamins.

Pollaroli, C., \& Rocci, A. (2015). The argumentative relevance of pictorial and multimodal metaphor in advertising. Journal of Argumentation in Context, 4(2), 158-200.

Pontecorvo, C., \& Girardet, H. (1993). Arguing and reasoning in understanding historical topics. Cognition and Instruction, 11(3-4), 211-227.

Rigotti, E. (2009). Whether and how classical topics can be revived within contemporary argumentation theory. In F. H. van Eemeren, \& B. Garssen (Eds.), Pondering on problems of argumentation (pp.157-178). Dordrecht: Springer.

Rigotti, E., \& Greco Morasso, S. (2010). Comparing the Argumentum Model of Topics to other contemporary approaches to argument schemes: The procedural and material components. Argumentation, 24(4), 489-512.

Sadler, T. D. (2004). Informal reasoning regarding socioscientific issues: A critical review of research. Journal of Research in Science Teaching, 41(5), 513-536.

Sadler, T. D. (2006). Promoting discourse and argumentation in science teacher education. Journal of Science Teacher Education, 17(4), 323-346.

Sadler, T. D., \& Zeidler, D. L. (2005). The significance of content knowledge for informal reasoning regarding socioscientific issues: Applying genetics knowledge to genetic engineering issues. Science Education, 89(1), 71-93.

Sampson, V., \& Clark, D. (2008). Assessment of the ways students generate arguments in science education: Current perspectives and recommendations for future directions. Science Education, 92(3), 447-472.

Sandoval, W. A., \& Millwood, K. (2005). The quality of students' use of evidence in written scientific explanations. Cognition and Instruction, 23(1), 23-55.

Sandoval, W. A., \& Reiser, B. J. (2004). Explanation-driven inquiry: Integrating conceptual and epistemic scaffolds for scientific inquiry. Science Education, 88(3), 345-372.

Schwarz, B. B., Neuman, Y., \& Biezuner, S. (2000). Two wrongs may make a right...if they argue! Cognition and Instruction, 18(4), 461-494.

Stein, N. L., \& Albro, E. R. (2001). The origins and nature of arguments: Studies in conflict understanding, emotion and negotiation. Discourse Processes, 32(2-3), 113-133.

von Aufschnaiter, C., Osborne, J., Erduran, J., \& Simon, S. (2008), Arguing to learn and learning to argue: Case studies of how students' argumentation relates to their scientific knowledge. Journal of Research in Science Teaching, 45(1), 101-131.

Walton, D. N. (1997). Appeal to expert opinion. Arguments from authority. University Park, PA: Pennsylvania State University Press.

Wiley, J., \& Voss, J. F. (1999). Constructing arguments from multiple sources: tasks that promote understanding and not just memory for text. Journal of Educational Psychology, 91(2), 301311.

Zohar, A., \& Nemet, F. (2002). Fostering students' knowledge and argumentation skills through dilemmas in human genetics. Journal of Research in Science Teaching, 39(1), 35-62. 